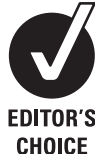

CHOICE

\title{
Early life origins of chronic obstructive pulmonary disease
}

\author{
C Svanes, ${ }^{1,2} \mathrm{~J}$ Sunyer, ${ }^{2,3}$ E Plana, ${ }^{2}$ S Dharmage, ${ }^{4} \mathrm{~J}$ Heinrich, ${ }^{5} \mathrm{D}$ Jarvis, ${ }^{6} \mathrm{R}$ de Marco, ${ }^{7}$ \\ D Norbäck, ${ }^{8} \mathrm{C}$ Raherison, ${ }^{9} \mathrm{~S}$ Villani, ${ }^{10} \mathrm{M}$ Wjst ${ }^{5} \mathrm{~K}$ Svanes, ${ }^{11} \mathrm{~J} \mathrm{M}$ Antón ${ }^{2,3}$
}

\section{See Editorial, p 1}

- Additional information is published online only at http:// thorax.bmj.com/content/vol65/ issue1

${ }^{1}$ Section of Thoracic Medicine Institute of Medicine, University of Bergen, Norway; ${ }^{2}$ Centre Recerca Epidemiologia Ambiental (CREAL-IMIM), Barcelona, Spain; ${ }^{3}$ Universitat Pompeu Fabra, Barcelona, Spain; ${ }^{4}$ Centre for MEGA Epidemiology, School of

Population Health, The University of Melbourne, Australia;

${ }^{5}$ Helmholtz Zentrum Munchen, National Research Center for Environmental Health, Institute of Epidemiology, Germany;

${ }^{6}$ Department of Public Health

Sciences, Imperial College,

London, UK; ${ }^{7}$ Department of

Medicine and Public Health/

Epidemiology and Medical

Statistics, University of Verona

Italy; ${ }^{8}$ Department of Medical

Science/Occupational and

Environmental Medicine,

Uppsala University, Sweden;

${ }^{9}$ INSERM U700 -

Epidémiologie, Faculté de

Médecine Xavier Bichat, Paris,

France; ${ }^{10}$ Department of Health

Sciences, Section of Medical

Statistics of Epidemiology,

University of Pavia, Italy;

${ }^{11}$ Institute of Surgery, University of Bergen, Norway

Correspondence to:

Dr C Svanes, Department of Occupational Medicine, 5021

Haukeland University Hospital,

Norway; cecilie.svanes@med. uib.no

Received 3 January 2009 Accepted 4 August 2009 Published Online First

12 October 2009

\begin{abstract}
Background: Early life development may influence subsequent respiratory morbidity. The impact of factors determined in childhood on adult lung function, decline in lung function and chronic obstructive pulmonary disease (COPD) was investigated.
\end{abstract}

Methods: European Community Respiratory Health Survey participants aged 20-45 years randomly selected from general populations in 29 centres underwent spirometry in 1991-3 $(n=13359)$ and 9 years later $(n=7738)$. Associations of early life factors with adult forced expiratory volume in $1 \mathrm{~s}\left(\mathrm{FEV}_{1}\right), \mathrm{FEV}_{1}$ decline and COPD (FEV $/ / F V C$ ratio $<70 \%$ and $\mathrm{FEV}_{1}<80 \%$ predicted) were analysed with generalised estimating equation models and random effects linear models.

Results: Maternal asthma, paternal asthma, childhood asthma, maternal smoking and childhood respiratory infections were significantly associated with lower $\mathrm{FEV}_{1}$ and defined as "childhood disadvantage factors"; $40 \%$ had one or more childhood disadvantage factors which were associated with lower $\mathrm{FEV}_{1}$ (men: adjusted difference $95 \mathrm{ml}(95 \% \mathrm{Cl} 67$ to 124); women: adjusted difference $60 \mathrm{ml}\left(95 \% \mathrm{Cl} 40\right.$ to 80)). $\mathrm{FEV}_{1}$ decreased with increasing number of childhood disadvantage factors $(\geqslant 3$ factors, men: $274 \mathrm{ml}$ (95\% Cl 154 to 395), women: $208 \mathrm{ml}(95 \% \mathrm{Cl} 124$ to 292)). Childhood disadvantage was associated with a larger $\mathrm{FEV}_{1}$ decline $(1$ factor: $2.0 \mathrm{ml}(95 \% \mathrm{Cl} 0.4$ to 3.6$)$ per year; 2 factors: $3.8 \mathrm{ml}$ (95\% Cl 1.0 to 6.6$) ; \geqslant 3$ factors: $2.2 \mathrm{ml}(95 \% \mathrm{Cl}-4.8$ to 9.2)). COPD increased with increasing childhood disadvantage (1 factor, men: OR 1.7 (95\% Cl 1.1 to 2.6), women: OR $1.6(95 \% \mathrm{Cl} 1.01$ to 2.6$)$; $\geqslant 3$ factors, men: OR 6.3 (95\% Cl 2.4 to 17), women: OR 7.2 (95\% Cl 2.8 to 19)). These findings were consistent between centres and when subjects with asthma were excluded.

Conclusions: People with early life disadvantage have permanently lower lung function, no catch-up with age but a slightly larger decline in lung function and a substantially increased COPD risk. The impact of childhood disadvantage was as large as that of heavy smoking. Increased focus on the early life environment may contribute to the prevention of COPD.

Early life environment is most important for the development of asthma and atopy, ${ }^{1-3}$ but there has been less focus on early life origins of chronic obstructive pulmonary disease (COPD)..$^{146}$ The development of the bronchial tree is completed in terms of numbers of terminal bronchioles by the first trimester of pregnancy. ${ }^{7}$ The final number of alveoli is established by the age of 2 years. ${ }^{7}$ Thereafter, growth and functional development of the bronchial tree and the alveoli continue until a plateau phase is reached by the end of adolescence in women ${ }^{9}$ and in the mid-20s in men..$^{10}{ }^{11}$ It seems plausible that this period of development and growth of the lungs might be important for lung function and the development of COPD later in life. ${ }^{5}$

While smoking is a very important determinant for adult lung function and COPD, there is a wide variation in adult lung function that is not related to smoking ${ }^{12}$ and that could possibly be explained by factors already determined early in life..$^{13}$ Maternal smoking is associated with lower lung function in infancy, ${ }^{14-16}$ childhood $^{17}$ and adulthood. ${ }^{18-20}$ An association between lower respiratory infections and adult lung function impairment is reasonably well documented..$^{561-23}$ Birth weight is consistently although weakly associated with lower adult lung function. ${ }^{54}{ }^{25}$ Childhood asthma is related to lower lung function in early adult life. ${ }^{46-28}$

This study examined the extent to which adult lung function and COPD are already determined in childhood compared with the impact of active smoking. We first identified early life environmental and genetic factors consistently associated with lower adult lung function; these were denoted "childhood disadvantage factors". We then investigated associations of childhood disadvantage with the level of adult lung function, lung function decline and COPD, and compared the impact of these with the impact of smoking. The analyses were performed using the European Community Respiratory Health Survey (ECRHS), a multicultural population from centres with wide variations in prevalence of COPD,${ }^{12}$ and included standardised spirometry measurements and extensive interview data for over 13000 adults aged 20-56 years.

\section{METHODS}

\section{Study subjects}

The ECRHS II is the follow-up study of participants in ECRHS I, which selected adults aged 20-44 years from the general population in 1991-3. A total of 13359 subjects (6624 men and 6735 women; 85\% of those eligible) were included from random samples from 29 centres with lung function at ECRHS I. Of these, $7738(57.9 \%)$ in 28 centres had lung function measured at ECRHS II in 1998-2002. ${ }^{29}$ The mean follow-up time was 8.9 years (interquartile range $8.3-$ 9.5) and the age range at follow-up was $26-56$ years. The full protocol can be found at www.ecrhs.org.

\section{Design}

The investigation of lung function level and COPD was cross-sectional using data from both ECRHS I and II. Subjects only participating in ECRHS I contributed with one measurement, subjects participating in both surveys contributed with two measurements. 
Longitudinal analysis of lung function decline was performed for subjects with lung function data in both surveys.

\section{Childhood disadvantage}

Participants responded to face-to-face interviewer-administered questionnaires including questions on early life factors, asthma and respiratory symptoms, and smoking habits. All available information in ECRHS I concerning early life (parental asthma, parental atopy, childhood asthma, childhood respiratory infections, parental smoking, family size and birth order, day care attendance, pet keeping and season of birth) was used for analysis. The questions are presented at www.ecrhs.org. "Childhood asthma" was defined as ever asthma with onset at or before the age of 10 years. Factors associated with adult forced expiratory volume in $1 \mathrm{~s}\left(\mathrm{FEV}_{1}\right)$ in both men and women at a significance level of $\mathrm{p} \leqslant 0.01$ after adjusting for smoking, education, social class, height, age and centre were defined as "childhood disadvantage factors". These factors were counted to create the variable "number of childhood disadvantage factors".

\section{Lung function measurements and definition of COPD}

The maximum $\mathrm{FEV}_{1}$ and maximum forced vital capacity (FVC) of up to five technically acceptable manoeuvres were determined, and whether FEV 1 and FVC each met the American Thoracic Society
(ATS) criterion for reproducibility. Decline in $\mathrm{FEV}_{1}$ was expressed per year of follow-up (ECRHS II value minus ECRHS I value; a negative value represents a decline). COPD was defined as having an $\mathrm{FEV}_{1} / \mathrm{FVC}$ ratio $<70 \%$ and $\mathrm{FEV}_{1}<80 \%$ of predicted, similar to GOLD stage 2 "clinically significant COPD". ${ }^{30}$ Postbronchodilator tests were not performed because the subjects underwent methacholine tests of bronchial hyperreactivity, so the definition of COPD was based on prebronchodilator measurements.

Twenty-two centres used the same spirometer in ECRHS I and II, mostly with updated software on the second occasion. Two centres used a SensorMedics dry spirometer on one occasion (SensorMedics, Yorba Linda, California, USA) and a Jaeger Masterscope (Würzburg, Germany) on the other. Two used a Jaeger Pneumotach at each survey, but not the same instrument. A fifth used a SensorMedics spirometer and SensorMedics Vmax 22. None of these differences in equipment led to heterogeneity in change in lung function compared with other centres. However, in one centre (Melbourne) a Pneumotach was used in ECRHS I and a rolling seal spirometer (SensorMedics) in ECRHS II, resulting in an apparent increase in lung function; thus only data from the first survey were used. Measurements in participants aged 20-26 years were from ECRHS I, measurements at age 26-44 years were from both surveys and measurements at age 44-56 years were from ECRHS II.

Table 1 Frequency (\%) of all childhood factors registered in ECRHS I and association of each factor with adult forced expiratory volume in $1 \mathrm{~s}\left(\mathrm{FEV}_{1}\right) \dagger$

\begin{tabular}{|c|c|c|c|c|}
\hline & \multicolumn{2}{|l|}{ Men } & \multicolumn{2}{|c|}{ Women } \\
\hline & $\%$ & $\begin{array}{l}\text { Adjusted difference in } \mathrm{FEV}_{1} \neq(\mathrm{ml}) \\
(95 \% \mathrm{Cl})\end{array}$ & $\%$ & $\begin{array}{l}\text { Adjusted difference in } \mathrm{FEV}_{1} 末(\mathrm{ml}) \\
(95 \% \mathrm{Cl})\end{array}$ \\
\hline Maternal asthma & 5.3 & $-74.5(-133 \text { to }-16.3)^{*}$ & 7.2 & $-44.0(-79.3 \text { to }-8.6)^{*}$ \\
\hline Paternal asthma & 5.7 & $-113(-169 \text { to }-56.3)^{*}$ & 6.4 & $-69.6(-107 \text { to }-31.8)^{*}$ \\
\hline Maternal atopy & 17.1 & $7.8(-28.0$ to 43.5$)$ & 22.6 & $-2.7(-25.1$ to 19.7$)$ \\
\hline Paternal atopy & 12.8 & $-14.0(-54.5$ to 26.4$)$ & 16.7 & $-12.5(-38.1$ to 13.1$)$ \\
\hline Childhood asthma & 4.1 & $-290(-352 \text { to }-227)^{*}$ & 2.9 & $-186(-239 \text { to }-133)^{*}$ \\
\hline $\begin{array}{l}\text { Severe respiratory } \\
\text { infection }<5 \text { years }\end{array}$ & 9.5 & $-108(-152 \text { to }-63.2)^{*}$ & 10.8 & $-50.6(-80.5 \text { to }-20.6)^{*}$ \\
\hline Maternal smoking & 24.1 & $-51.4(-82.5 \text { to }-20.3)^{*}$ & 25.9 & $-28.3(-50 \text { to }-6.7)^{*}$ \\
\hline Paternal smoking & 66.3 & $-19.6(-47.3$ to 8.0$)$ & 65.5 & $-4.4(-24.1$ to 15.3$)$ \\
\hline \multicolumn{5}{|l|}{ Number of siblings } \\
\hline 0 & 10.8 & & 10.0 & \\
\hline 1 & 30.6 & $19.2(-26.0$ to 64.4$)$ & 30.6 & $15.2(-17.5$ to 47.9$)$ \\
\hline 2 & 25.4 & $26.7(-20.3$ to 73.6$)$ & 25.4 & $25.5(-8.2$ to 59.1$)$ \\
\hline 3 & 15.3 & $18.4(-33.4$ to 70.1$)$ & 15.3 & $-0.1(-36.9$ to 36.7$)$ \\
\hline$\geqslant 4$ & 18.0 & $9.6(-40.8$ to 60.0$)$ & 18.8 & $8.1(-27.8$ to 44.1$)$ \\
\hline \multicolumn{5}{|l|}{ Order of birth } \\
\hline $1^{\text {st }}$ & 42.2 & & 39.9 & \\
\hline $2^{\text {nd }}$ & 29.7 & $12.0(-18.6$ to 42.6$)$ & 29.7 & $19.0(-2.8$ to 40.8$)$ \\
\hline $3^{\text {rd }}$ & 14.5 & $33.2(-5.9$ to 72.3$)$ & 16.4 & $18.5(-8.1$ to 45.1$)$ \\
\hline$>3^{\text {rd }}$ & 13.6 & $-8.2(-48.3$ to 32.0$)$ & 14.0 & $21.4(-7.1$ to 49.7$)$ \\
\hline Day care & 48.6 & $-10.8(-39.1$ to 17.5$)$ & 46.0 & $5.8(-14.6$ to 26.2$)$ \\
\hline \multicolumn{5}{|l|}{ Pets } \\
\hline No pet & 37.7 & & 36.2 & \\
\hline Cat & 16.6 & $1.5(-37.1$ to 40.1$)$ & 18.0 & 31.3 (4.6 to 58 ) \\
\hline Dog & 18.2 & $-11.6(-48.8$ to 25.6$)$ & 16.8 & $8.1(-18.9$ to 35.1$)$ \\
\hline Cat and dog & 27.5 & $13.4(-20.3$ to 47.1$)$ & 29.0 & 28.3 (4.6 to 52 ) \\
\hline \multicolumn{5}{|l|}{ Season of birth } \\
\hline Spring & 25.9 & & 26.5 & \\
\hline Summer & 24.4 & $8.4(-27.5$ to 44.2$)$ & 24.9 & $8.4(-16.8$ to 33.5$)$ \\
\hline Autumn & 23.9 & $8.1(-28.0$ to 44.2$)$ & 22.9 & $19.1(-6.6$ to 44.8$)$ \\
\hline Winter & 25.8 & 42.0 (6.7 to 77.3$)$ & 25.8 & $3.6(-21.3$ to 28.5$)$ \\
\hline
\end{tabular}

Analyses include 8201 measurements in men and 8631 measurements in women with complete data.

${ }^{*} \mathrm{p} \leqslant 0.01$.

$\uparrow$ As measured in ECRHS I and ECRHS II.

tDifference in $\mathrm{FEV}_{1}$ between subjects with and without childhood factor as analysed in separate models and adjusted for smoking status, age at completed education, social class, age, height and centre. 
Table 2 Associations of adult forced expiratory volume in $1 \mathrm{~s}\left(\mathrm{FEV}_{1}\right)^{*}$ with $(\mathrm{A})$ individual childhood disadvantage factors and $(B)$ the number of childhood disadvantage factors

\begin{tabular}{|c|c|c|c|c|}
\hline & \multicolumn{2}{|l|}{ Men } & \multicolumn{2}{|l|}{ Women } \\
\hline & $\begin{array}{l}\text { Adjusted difference in } \mathrm{FEV}_{1} \dagger \\
\text { (ml) }(95 \% \mathrm{Cl})\end{array}$ & p Value & $\begin{array}{l}\text { Adjusted difference in } \mathrm{FEV}_{1} \dagger \\
\text { (ml) }(95 \% \mathrm{CI})\end{array}$ & p Value \\
\hline \multicolumn{5}{|l|}{ (A) } \\
\hline Baseline $\mathrm{FEV}_{1}(\mathrm{ml})$ : & 4383 & & 3191 & \\
\hline Maternal asthma & $-49.2(-111.6$ to 13.3$)$ & 0.123 & $-24.7(-61.9$ to 12.5$)$ & 0.193 \\
\hline Paternal asthma & $-102(-161$ to -43.2$)$ & $<0.001$ & $-58.2(-96.9$ to -19.6$)$ & 0.003 \\
\hline Childhood asthma & $-288(-360$ to -216$)$ & $<0.001$ & $-147(-204$ to -89.0$)$ & $<0.001$ \\
\hline $\begin{array}{l}\text { Severe respiratory infection }<5 \\
\text { years }\end{array}$ & $-70.1(-117.1$ to -23.2$)$ & 0.003 & $-28.2(-59.5$ to 3.1$)$ & 0.077 \\
\hline $\begin{array}{l}\text { Maternal smoking } \\
\text { (B) }\end{array}$ & $-44.5(-77.9$ to -11.2$)$ & 0.009 & $-30.5(-53.4$ to -7.6$)$ & 0.009 \\
\hline Baseline $\mathrm{FEV}_{1}(\mathrm{ml}):$ & 4372 & & 3198 & \\
\hline \multicolumn{5}{|l|}{$\begin{array}{l}\text { Number of childhood } \\
\text { disadvantage factors }\end{array}$} \\
\hline 1 & $-58.0(-87.0$ to -29.1$)$ & $<0.001$ & $-48.9(-68.9$ to -28.8$)$ & $<0.001$ \\
\hline 2 & $-201(-253$ to -149$)$ & $<0.001$ & $-78.4(-113$ to -43.5$)$ & $<0.001$ \\
\hline$\geqslant 3$ & $-274(-395$ to -154$)$ & $<0.001$ & $-208(-292$ to -124$)$ & $<0.001$ \\
\hline \multicolumn{5}{|l|}{ For comparison§ } \\
\hline \multicolumn{5}{|l|}{ Adult smoking status } \\
\hline Ex & $2.0(-28.5$ to 32.4$)$ & 0.900 & 29.7 (8.8 to 50.6$)$ & 0.005 \\
\hline Current $<10 \mathrm{cig} /$ day & $-45.8(-81.0$ to -10.6$)$ & 0.011 & $-6.7(-30.4$ to 17.1$)$ & 0.583 \\
\hline Current $10-20 \mathrm{cig} / \mathrm{day}$ & $-77.0(-114$ to -40.5$)$ & $<0.001$ & $-16.5(-42.6$ to 9.6$)$ & 0.215 \\
\hline Current $>20 \mathrm{cig} /$ day & $-112(-149$ to -74.9$)$ & $<0.001$ & $-75.6(-105$ to -45.8$)$ & $<0.001$ \\
\hline \multicolumn{5}{|c|}{$\begin{array}{l}\text { Analyses include } 8201 \text { measurements in men and } 8631 \text { measurements in women with complete data. } \\
{ }^{*} \text { As measured in ECRHS I and ECRHS II. } \\
\text { †Difference in FEV } \mathrm{F}_{1}(\mathrm{~A}) \text { between subjects with and subjects without childhood factor when adjusting for other childhood factors in } \\
\text { the table and (B) between subjects with a specific number of childhood factors and subjects with zero childhood factors. Adjusted } \\
\text { for smoking status, age at completed education, social class, age, height and centre. } \\
\text { \$Baseline FEV } \mathrm{FV}_{1} \text { in never-smoking, high education, professional subjects of median age and median height with none of the } \\
\text { childhood disadvantage factors. } \\
\text { \$Estimates for adult smoking are presented in order to enable comparison of estimates. The estimates are from model B, but are } \\
\text { practically identical in model A. }\end{array}$} \\
\hline
\end{tabular}

\section{Smoking and covariates}

Smokers were categorised as never-, ex- and current smokers; current smokers were further categorised based on the number of cigarettes smoked daily $(<10,10-20, \geqslant 20)$. Height and weight were measured before spirometry and body mass index (BMI) was calculated from these as weight/height ${ }^{2}$. Age when completing formal education defined "education". The last job in the occupational history defined social class. "Current adult asthma" was defined as asthma attacks during the last 12 months and/or current asthma medication. The question "Have you ever had asthma?" defined "ever asthma". "Wheeze" was defined as wheezing/whistling in the chest during the last 12 months when not having a cold. Allergen-specific IgEs were measured using the Pharmacia CAP system. Assays for allergen-specific IgE were considered positive when exceeding $0.35 \mathrm{kU} / \mathrm{l}$. Atopy was defined as specific IgE to cat dander, house dust mite (Dermatophagoides pteronyssinus), timothy grass and/or Cladosporium herbarum.

\section{Statistical analysis}

The association of each childhood factor with adult $\mathrm{FEV}_{1}$ and FVC was analysed using generalised estimating equation (GEE) models, allowing for dependency between two lung function measurements of the same individual. Adjustments were made for age, height, smoking, education, social class and centre using information about height and social class from ECRHS I and information about age, smoking and education from the same survey as the lung function measurement. Similar models were used to analyse the mutually adjusted associations between lung function and the childhood factors significantly $(p \leqslant 0.01)$ associated with $\mathrm{FEV}_{1}$ in both men and women, and the associations of lung function with number of childhood disadvantage factors.

$\mathrm{FEV}_{1}$ by age curves were fitted using generalised additive models (GAM) with adjustment for sex, height and smoking.

The associations of childhood factors with lung function decline were tested using mixed effects linear regression models with adjustment for $\mathrm{FEV}_{1}$ at baseline, mid age, mid age ${ }^{2}$, height, difference in BMI, mid BMI, sex, the interaction between sex and change in BMI, smoking at ECRHS II and centre adjusted for as a random effect due to heterogeneity across centres. ${ }^{30}$ Men and women were analysed together as the power for analysis of lung function decline was limited in this relatively young population and there were not significant interactions by gender.

Associations of each childhood factor and of the number of childhood factors with COPD were analysed using GEE models for binary data, allowing for dependency between two lung function measurements in the same individual and adjusting for age, height, smoking, education, social class and country.

\section{RESULTS}

The level of $\mathrm{FEV}_{1}$ and decline in $\mathrm{FEV}_{1}$ per year of follow-up for men and women and according to all early life factors are given in table 1 in the online supplement. The adjusted associations of each childhood factor with adult $\mathrm{FEV}_{1}$ are shown in table 1. Maternal asthma, paternal asthma, childhood asthma, respiratory infections and maternal smoking were associated with adult $\mathrm{FEV}_{1}$ in both men and women $(\mathrm{p} \leqslant 0.01$, table 1$)$; these factors defined "childhood disadvantage".

Childhood disadvantage was highly prevalent in the population; $40 \%$ of all subjects had one or more such factors including 
Figure 1 Forced expiratory volume in $1 \mathrm{~s}\left(\mathrm{FEV}_{1}\right)$ by age according to number of childhood disadvantage factors in (A) men and (B) women (adjusted for smoking and height); in (C) neversmokers and (D) current smokers (adjusted for sex and height); and in (E) non-symptomatic subjects and (F) subjects who had never had asthma (childhood asthma excluded from childhood disadvantage factors) (adjusted for smoking, sex, and height). The curves were fitted using generalised additive models, based on $\mathrm{FEV}_{1}$ measurements from both ECRHS I and ECRHS II for the age range 26-44 years, only ECRHS I measurements at ages 20-26 years and only ECRHS II measurements at age 4556 years.
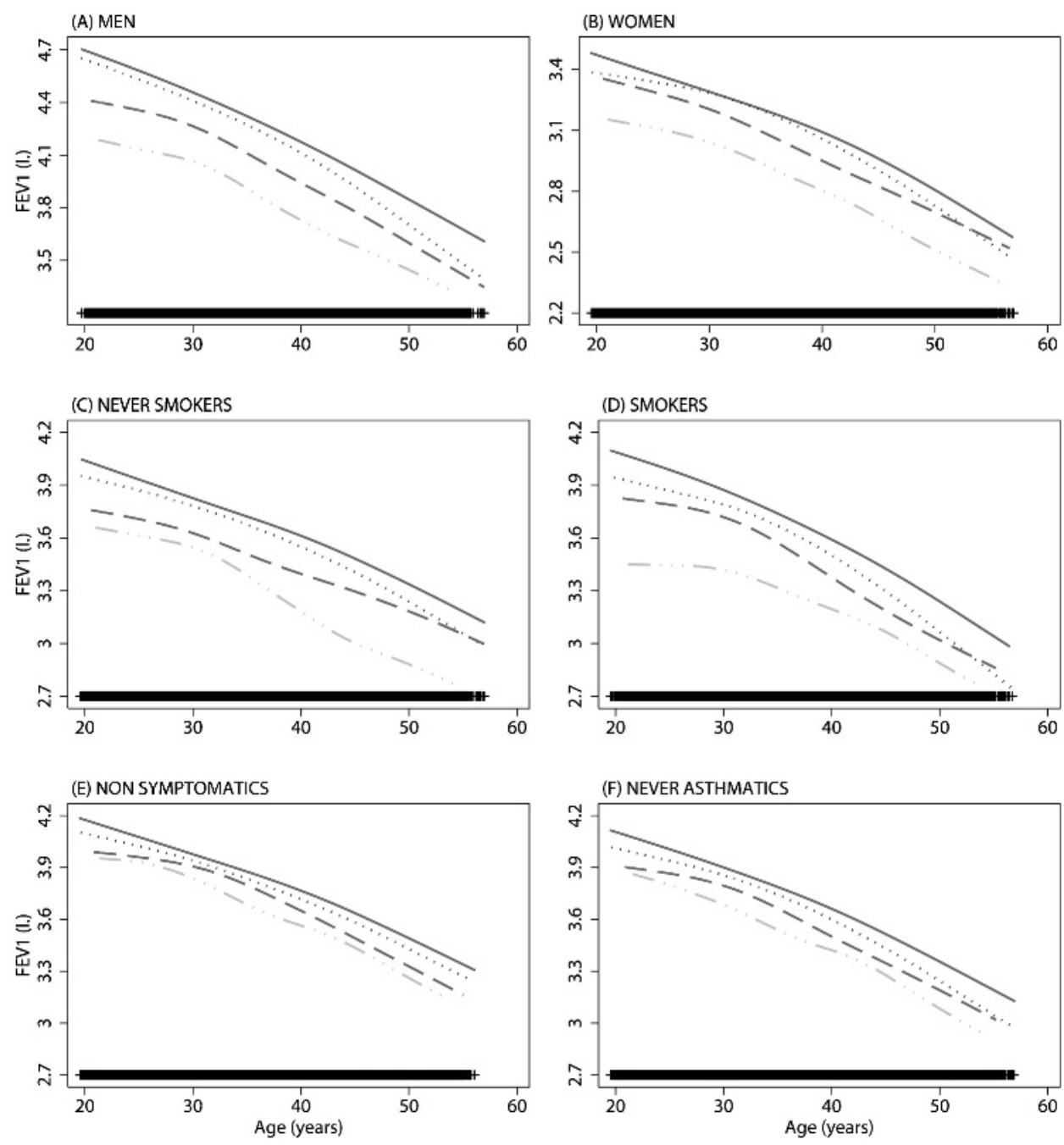

Number of childhood factors

$0 \quad \ldots \ldots \ldots$.
$32 \%$ with one factor, $7.4 \%$ with two factors and $1.2 \%$ with three or more factors. Population characteristics varied little with childhood disadvantage while adult asthma, wheeze and atopy were increasingly prevalent with a higher number of childhood disadvantage factors (see table 2 in online supplement).

When mutually adjusting for other childhood disadvantage factors (table 2), the associations of paternal asthma, childhood asthma and maternal smoking with $\mathrm{FEV}_{1}$ were practically unchanged and remained highly significant. The estimates for each childhood factor were comparable to or larger than the estimate for smoking 10-19 cigarettes daily. $\mathrm{FEV}_{1}$ was consecutively lower with a higher number of childhood disadvantage factors in both men and women. Having two or more childhood disadvantage factors (8.6\%) was almost as common in the population as heavy smoking (10.4\%) and associated with a larger lung function deficit. Adjustment for current respiratory symptoms, asthma or atopy did not alter this conclusion (see table 3 in online supplement). Lower $\mathrm{FEV}_{1}$ in subjects with one or more childhood disadvantage factors (men: $95 \mathrm{ml}$ (95\% CI 67 to 124); women: $60 \mathrm{ml}$ (95\% CI 40-80)) was consistent between centres (men: $p_{\text {heterogeneity }}=0.34$; women: $p_{\text {heterogeneity }}=0.24$; fig 1 in online supplement). When excluding subjects with childhood asthma (childhood disadvantage thus consisting of four factors), the effects of childhood disadvantage on adult lung function were still highly significant and stronger than those of smoking (see table $4 \mathrm{a}$ in online supplement).

$\mathrm{FEV}_{1}$ became lower with increasing childhood disadvantage (fig 1), which was similar for all ages. The pattern was similar for men and women (fig $1 \mathrm{~A}$ and $\mathrm{B}$ ) and for never-smokers and current smokers (fig $1 \mathrm{C}$ and D). No significant interaction with gender or smoking was detected $(p>0.1)$. The findings were similar when subjects reporting current respiratory symptoms and/or asthma were excluded (fig 1E) and when subjects who had ever had asthma were excluded (fig 1F).

FVC was significantly lower in men and women with two childhood disadvantage factors and decreased significantly in subjects with an increasing number of childhood disadvantage factors (table 3). The association of childhood disadvantage with FVC was substantially weaker than that observed for $\mathrm{FEV}_{1}$.

The decline in $\mathrm{FEV}_{1}$ was $2 \mathrm{ml}$ (95\% CI 0.4 to 3.6) larger per year in subjects with one childhood disadvantage factor, $3.8 \mathrm{ml}$ (95\% CI 1.0 to 6.6) larger in those with two factors and $2.2 \mathrm{ml}$ ( $95 \%$ CI -4.8 to 9.2 ) larger in those with $\geqslant 3$ factors; the decline increased with an increasing number of childhood disadvantage factors (table 4). For comparison, smoking 10-20 cigarettes daily was associated with a $4 \mathrm{ml}$ larger decline in lung function per year (table 4). When subjects with childhood asthma were excluded the findings were similar (see table $4 \mathrm{~b}$ in the online 
Table 3 Associations of adult forced vital capacity $(\mathrm{FVC})^{*}$ with $(\mathrm{A})$ individual childhood disadvantage factors and $(B)$ the number of childhood disadvantage factors

\begin{tabular}{|c|c|c|c|c|}
\hline & \multicolumn{2}{|l|}{ Men $(\mathrm{N}=8201)$} & \multicolumn{2}{|l|}{ Women ( $N=8633$ ) } \\
\hline & $\begin{array}{l}\text { Adjusted difference in } \mathrm{FVC} \uparrow \\
(\mathrm{ml})(95 \% \mathrm{Cl})\end{array}$ & p Value & $\begin{array}{l}\text { Adjusted difference in FVC } \dagger \\
(\mathrm{mI})(95 \% \mathrm{Cl})\end{array}$ & p Value \\
\hline \multicolumn{5}{|l|}{ (A) } \\
\hline Baseline FVC (ml): & 5347.3 & & 3838.7 & \\
\hline Maternal asthma & $2.0(-70.8$ to 74.7$)$ & 0.957 & $19.0(-25.1$ to 63.1$)$ & 0.398 \\
\hline Paternal asthma & $-21.5(-90.4$ to 47.3$)$ & 0.540 & $-44.8(-90.7$ to 1.0$)$ & 0.055 \\
\hline Childhood asthma & $-47.0(-130.9$ to 36.9$)$ & 0.272 & $-119.6(-188.0$ to -51.2$)$ & 0.001 \\
\hline $\begin{array}{l}\text { Severe respiratory infection before } \\
5 \text { years }\end{array}$ & $-37.5(-92.3$ to 17.2$)$ & 0.179 & $-31.0(-68.2$ to 6.1$)$ & 0.101 \\
\hline $\begin{array}{l}\text { Maternal smoking } \\
\text { (B) }\end{array}$ & $-7.0(-45.9$ to 31.9$)$ & 0.724 & $-8.8(-36.0$ to 18.4$)$ & 0.524 \\
\hline Baseline FVC (ml): & 5341.6 & & 3840.4 & \\
\hline \multicolumn{5}{|l|}{ Number of childhood factors } \\
\hline 1 & $-6.4(-39.9$ to 27.1$)$ & 0.709 & $-24.4(-48.0$ to -0.8$)$ & 0.043 \\
\hline 2 & $-60.0(-120.0$ to -0.1$)$ & 0.050 & $-44.8(-85.9$ to -3.6$)$ & 0.033 \\
\hline 3 & $-64.6(-204.2$ to 75.0$)$ & 0.364 & $-177.5(-276.4$ to -78.6$)$ & $<0.001$ \\
\hline \multicolumn{5}{|l|}{ For comparison: } \\
\hline \multicolumn{5}{|l|}{ Adult smoking status } \\
\hline Former & $34.6(-2.5$ to 71.7$)$ & 0.067 & 55.8 (30.1 to 81.4$)$ & $<0.001$ \\
\hline Current $<10 \mathrm{cig} /$ day & $-25.4(-69.0$ to 18.2$)$ & 0.253 & $14.0(-15.5$ to 43.5$)$ & 0.352 \\
\hline Current $10-20 \mathrm{cig} / \mathrm{day}$ & $-15.8(-61.0$ to 29.5$)$ & 0.495 & 37.7 (5.1 to 70.2$)$ & 0.023 \\
\hline Current $>20 \mathrm{cig} /$ day & $-71.9(-117.2$ to -26.5$)$ & 0.002 & $-12.9(-50.1$ to 24.3$)$ & 0.497 \\
\hline \multicolumn{5}{|c|}{$\begin{array}{l}\text { Analyses include } 8201 \text { measurements in men and } 8633 \text { measurements in women with complete data. } \\
{ }^{*} \text { As measured in ECRHS I and ECRHS II. } \\
\text { †Difference in FVC (A) between subjects with and subjects without childhood factor when adjusting for other childhood factors in } \\
\text { the table and (B) between subjects with a specific number of childhood factors and subjects with zero childhood factors. Adjusted } \\
\text { for smoking status, age at completed education, social class, age, height and centre. } \\
\$ \text { Baseline FVC in never-smoking, high education, professional subjects of median age and median height with none of the childhood } \\
\text { disadvantage factors. } \\
\text { §Estimates for adult smoking are presented in order to enable comparison of estimates. The estimates are from model B, but are } \\
\text { practically identical in model A. }\end{array}$} \\
\hline
\end{tabular}

supplement). Adjustment for current respiratory symptoms, asthma or atopy did not alter the findings (data not given).

Childhood asthma and paternal asthma were significantly associated with COPD (table 5). COPD increased with increasing childhood disadvantage in both men and women (table 5). The associations of COPD with childhood disadvantage were at least as strong as those with heavy smoking (table 5). When subjects with childhood asthma were excluded, COPD was still significantly associated with $2-3$ childhood disadvantage factors and with an increasing number of factors, but the associations were weaker (see table $4 \mathrm{c}$ in online supplement).

\section{DISCUSSION}

This analysis of a large multicentre population indicates that adult lung function and susceptibility to COPD is partly determined early in life, and that the impact of childhood disadvantage appears to persist. Maternal asthma, paternal asthma, childhood asthma, severe respiratory infections before the age of 5 years and maternal smoking were associated with a lower adult $\mathrm{FEV}_{1}$ level, and having any one or more of these factors constituted a considerable disadvantage with regard to adult lung function and COPD. Subjects with an increasing number of childhood disadvantage factors had an increasingly lower level of $\mathrm{FEV}_{1}$ in adult life, a slightly larger decline in $\mathrm{FEV}_{1}$ and the prevalence of COPD was substantially increased. The impairment of $\mathrm{FEV}_{1}$ persisted up to the maximum age in our study population (56 years) and no catch-up was detected. Childhood disadvantage was as common in the population as current smoking, and showed an equally large impact on lung function and COPD and a slightly smaller impact on lung function decline. These findings were similar for men and women, smokers and non-smokers, subjects who had never had asthma and non-symptomatic subjects, and were consistent across different geographical areas.

To our knowledge, no other studies have attempted to assess the overall impact of early life origins on adult lung function and COPD. Studies on single factors-in particular on childhood asthma, ${ }^{4}{ }^{27}$ lower respiratory infections ${ }^{5}{ }^{21-23}$ and maternal smoking ${ }^{18-20}$ - mostly agree that the respective factors affect the level of lung function in early adulthood but not the decline in lung function. The lack of association between the individual factors and a decline in lung function agrees with our findings; when we considered each risk factor separately there were only minor effects. However, when attempting to describe overall early life disadvantage by counting the number of disadvantage factors, a larger decline was revealed. Knowledge about early life origins of COPD is scarce. ${ }^{13}$ Our study has the advantages of being very large, including older subjects than most previous studies and investigating representative populations from many countries.

The main limitation of the present study is the retrospective nature of the information about early life. The accuracy of recalling childhood asthma by adults may be related to current symptoms. ${ }^{31}$ However, when excluding subjects with current symptoms or asthma, our findings remained unchanged. Also, in our study the outcome measures were objective and not yet perceived; this made differential recall bias less likely. Finally, it seems unlikely that recall error should cause spurious results in a consistent pattern across centres. A previous analysis revealed that adults reported important childhood events with high consistency regardless of symptom status. ${ }^{32}$ However, some random misclassification of early life factors due to nondifferential recall error is likely and will have attenuated the 
Table 4 Associations of decline in adult forced expiratory volume in $1 \mathrm{~s}\left(\mathrm{FEV}_{1}\right)^{*}$ with $(\mathrm{A})$ individual childhood disadvantage factors and $(\mathrm{B})$ the number of childhood disadvantage factors in 5608 subjects with complete data

\begin{tabular}{|c|c|c|}
\hline & $\begin{array}{l}\text { Adjusted decline in } \mathrm{FEV}_{1} \\
\left(\Delta \mathrm{FEV}_{1} \dagger, \mathrm{ml} / \mathrm{year}\right)(95 \% \mathrm{Cl})\end{array}$ & p Value \\
\hline \multicolumn{3}{|l|}{ (A) } \\
\hline Baseline decline $(\mathrm{ml} /$ year $) \$$ & -23.2 & \\
\hline Maternal asthma & $-0.5(-3.7$ to 2.7$)$ & 0.770 \\
\hline Paternal asthma & $-2.1(-5.3$ to 1.0$)$ & 0.186 \\
\hline Childhood asthma & $-5.9(-10.7$ to -1.2$)$ & 0.013 \\
\hline $\begin{array}{l}\text { Severe respiratory infection }<5 \\
\text { years }\end{array}$ & $-1.1(-3.6$ to 1.4$)$ & 0.385 \\
\hline $\begin{array}{l}\text { Maternal smoking } \\
\text { (B) }\end{array}$ & $-1.3(-3.2$ to 0.6$)$ & 0.175 \\
\hline Baseline decline $(\mathrm{ml} /$ year $) \$$ & -23.4 & \\
\hline \multicolumn{3}{|l|}{ Number of childhood factors } \\
\hline 1 & $-2.0(-3.6$ to -0.4$)$ & 0.014 \\
\hline 2 & $-3.8(-6.6$ to -1.0$)$ & 0.009 \\
\hline$\geqslant 3$ & $-2.2(-9.2$ to 4.8$)$ & 0.542 \\
\hline $\mathrm{p}$ for trend & 0.003 & \\
\hline \multicolumn{3}{|l|}{ For comparison: } \\
\hline \multicolumn{3}{|l|}{ Adult smoking status } \\
\hline Ex & 3.5 (1.8 to 5.3$)$ & $<0.001$ \\
\hline Current $<10 \mathrm{cig} /$ day & $-0.7(-3.7$ to 2.3$)$ & 0.639 \\
\hline Current $10-20 \mathrm{cig} /$ day & $-4.0(-6.9$ to -1.1$)$ & 0.006 \\
\hline Current $>20 \mathrm{cig} /$ day & $-9.5(-11.9$ to -7.0$)$ & $<0.001$ \\
\hline
\end{tabular}

${ }^{*}$ Decline in forced expiratory volume in $1 \mathrm{~s}$ in $\mathrm{ml}$ per year of follow-up (FEV ${ }_{1}$ in ECRHS II minus $\mathrm{FEV}_{1}$ in ECRHS I).

tDifference in decline in FEV ${ }_{1}$ in $\mathrm{ml}$ per year of follow-up (A) between subjects with and subjects without childhood factor when adjusting for other childhood factors in the table and (B) between subjects with a specific number of childhood factors and subjects with zero childhood factors. Adjusted for $\mathrm{FEV}_{1}$ at baseline, mid age, mid age ${ }^{2}$, height at ECRHS II, change in BMI, mid BMI, sex, interaction between sex and change in BMI, smoking, age at completed education, social class and centre as random effect.

$\$$ Baseline decline in $\mathrm{FEV}_{1}$ per year of follow-up in never-smoking, high education, professional subjects of median age, median height and median BMI with none of the childhood disadvantage factors.

§Estimates for adult smoking are presented in order to enable comparisons of estimates. The estimates are from model $B$, but are practically identical for model A.

associations, so the observed estimates may underestimate the true effects. Another problem of this study was a lack of information on potentially important factors such as childhood exposure to air pollution and childhood nutrition, which may also have contributed to an underestimate of the true importance of early life disadvantage. Only prebronchodilator spirometric measures were available. The findings were consistent when subjects who had ever had diagnosed asthma or currently had respiratory symptoms were excluded. However, the findings might relate to asymptomatic bronchoconstriction rather than to fixed airway damage; this should be investigated in future studies.

There are several possible mechanisms by which childhood disadvantage might influence adult lung function and development of COPD. Early life factors could reduce lung growth in utero and in early childhood and prevent individuals from ever reaching the potential maximum lung function level, as suggested by the observed associations with $\mathrm{FEV}_{1}$ and FVC. Early life environment might further influence physiological factors directly related to lung function throughout life (ie, by causing persistent inflammation). ${ }^{33}$ This could possibly explain the persistence of effects of childhood disadvantage in adulthood and the larger decline in lung function. Both lung growth impairment and persistent inflammation might explain the demonstrated higher risk of COPD in subjects with childhood disadvantage. Finally, early life factors might increase susceptibility to subsequent risk factors. In our study smoking did not interact with childhood disadvantage, so no increased vulnerability to smoking among subjects with childhood disadvantage was found.

One may question whether asthma was a mediator for the effects of childhood disadvantage on adult lung function and COPD. Lung function during childhood and adolescence is impaired in children with asthma, probably due to chronic inflammation and reduced lung growth. ${ }^{26}$ The role of childhood asthma in lung function decline is controversial, ${ }^{4}$ while it appears convincing that adult asthma is, after smoking, the most important risk factor for low $\mathrm{FEV}_{1} \cdot{ }^{34}{ }^{35}$ In the present study, childhood asthma showed the strongest associations with level of lung function when analysing each childhood disadvantage factor separately. However, the results remained practically unchanged when childhood asthma was excluded (see fig $2 \mathrm{~F}$ and online tables $4 \mathrm{~A}-\mathrm{C}$ ), and the observed associations with $\mathrm{FEV}_{1}$, decline in $\mathrm{FEV}_{1}$ and COPD were independent of current adult asthma (see fig $2 \mathrm{E}$ and online table 3). Thus, the effects of childhood disadvantage on adult lung function and COPD in this study were not mediated by asthma. On the other hand, the effects of early life factors on adult asthma may be a consequence of the impact on lung function development.

The definition of early life disadvantage in the present study implies a combination of genetic and environmental factors. A possible genetic effect might be captured by factors such as parental asthma. However, mother, father and child also share a common environment. While childhood asthma in itself may influence lung function, childhood asthma is also a result of genetic susceptibility. The environmental and genetic contributions of these factors cannot therefore easily be separated.

In conclusion, this study suggests that adult respiratory health to a large extent originates early in life. In the struggle to prevent COPD, intervention in early life in addition to smoking prevention might help abate the ongoing COPD epidemic. Programmes focusing on maternal smoking in pregnancy and the perinatal period are likely to be as beneficial as programmes reducing active smoking for decades in other periods of life. Treatment of childhood asthma might have long-term effects on $\mathrm{COPD},{ }^{36}$ and one may speculate whether vaccination against lower respiratory tract infections might also promote adult respiratory health. With regard to secondary prevention, followup of subjects with early life disadvantage should focus on special preventive measures against known environmental determinants for COPD. For instance, smoking prevention campaigns among teenagers could include determination of risk profiles and increase efforts in subjects with known childhood disadvantage. Given that almost half of the investigated western populations had one or more identifiable childhood disadvantage factors, this study implies that any improvement in early life environment may have large beneficial effects in the primary prevention of COPD.

Acknowledgements: The authors thank the ECRHS researchers listed in the online supplement, the ECRHS study participants and Professor Michael Abramson (Melbourne) for his very helpful revision of the paper.

Funding: A list of investigators and funding sources is given in the online supplement. Competing interests: None.

Ethics approval: Ethical approval was obtained for each centre from the appropriate institutional or regional ethics committee and written informed consent was obtained from each participant.

Provenance and peer review: Not commissioned; externally peer reviewed. 
Table 5 Associations of chronic obstructive pulmonary disease (COPD)* with (A) individual childhood disadvantage factors and $(B)$ with the number of childhood disadvantage factors

\begin{tabular}{|c|c|c|c|c|}
\hline & \multicolumn{2}{|l|}{ Men } & \multicolumn{2}{|l|}{ Women } \\
\hline & $\mathrm{OR} \uparrow(95 \% \mathrm{CI})$ & p Value & $\mathrm{OR} \dagger(95 \% \mathrm{Cl})$ & p Value \\
\hline (A) & 1 (reference) & & 1 (reference) & \\
\hline Maternal asthma & 1.26 (0.56 to 2.82$)$ & 0.576 & $1.55(0.73$ to 3.31$)$ & 0.255 \\
\hline Paternal asthma & 2.69 (1.53 to 4.74$)$ & 0.001 & $2.94(1.60$ to 5.41$)$ & 0.001 \\
\hline Childhood asthma & $10.48(6.10$ to 18.03$)$ & $<0.001$ & 3.74 (1.55 to 9.02$)$ & 0.003 \\
\hline $\begin{array}{l}\text { Severe respiratory infection } \\
\text { before } 5 \text { years }\end{array}$ & $1.34(0.77$ to 2.35$)$ & 0.303 & $0.69(0.31$ to 1.53$)$ & 0.362 \\
\hline $\begin{array}{l}\text { Maternal smoking } \\
\text { (B) }\end{array}$ & $1.41(0.89$ to 2.25$)$ & 0.143 & & \\
\hline \multicolumn{5}{|l|}{ Number of childhood factors } \\
\hline 0 (reference) & 1 (reference) & & 1 (reference) & \\
\hline 1 & 1.71 (1.10 to 2.64$)$ & 0.017 & 1.62 (1.01 to 2.60$)$ & 0.046 \\
\hline 2 & 5.23 (3.14 to 8.73$)$ & $<0.001$ & $2.41(1.26$ to 4.61$)$ & 0.008 \\
\hline 3 & 6.32 (2.35 to 16.98$)$ & $<0.001$ & $7.16(2.75$ to 18.64$)$ & $<0.001$ \\
\hline \multicolumn{5}{|l|}{ For comparison } \\
\hline \multicolumn{5}{|l|}{ Adult smoking status } \\
\hline Former & 2.44 (1.39 to 4.27$)$ & 0.002 & $1.00(0.51$ to 1.94$)$ & 0.999 \\
\hline Current $<10 \mathrm{cig} /$ day & $2.50(1.27$ to 4.91$)$ & 0.008 & $0.62(0.20$ to 1.88$)$ & 0.398 \\
\hline Current $10-20 \mathrm{cig} /$ day & 2.16 (1.07 to 4.34$)$ & 0.031 & 2.32 (1.16 to 4.66$)$ & 0.018 \\
\hline Current $>20 \mathrm{cig} /$ day & $3.70(2.05$ to 6.69$)$ & $<0.001$ & $3.82(2.04$ to 7.13$)$ & $<0.001$ \\
\hline
\end{tabular}

Analyses include 8201 measurements in men and 8633 measurements in women with complete data.

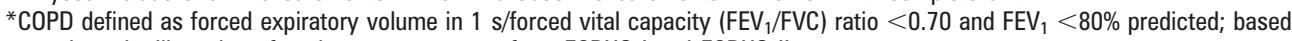
on prebronchodilator lung function measurements from ECRHS I and ECRHS II.

†Odds ratio (OR) for COPD (A) comparing subjects with and without each childhood factor when adjusting for other childhood factors in the table and (B) comparing subjects with a specific number of childhood factors with subjects with zero childhood factors. Adjusted for smoking status, age completed education, social class, age, height and centre.

FEstimates for adult smoking are presented in order to enable comparisons of estimates. The estimates are from model $B$, but are practically identical for model A.

\section{REFERENCES}

1. Speizer FE, Tager IB. Epidemiology of chronic mucus hypersecretion and obstructive airways disease. Epidemiol Rev 1979;1:124-42.

2. Eder W, Ege MJ, von Mutius E. The asthma epidemic. N Engl J Med 2006:355:2226-35

3. Svanes C, Jarvis D, Chinn S, et al. Childhood environment and adult atopy: results from the European Community Respiratory Health Survey. J Allergy Clin Immunol 1999;103:415-20.

4. Marossy AE, Strachan DP, Rudnicka AR, et al. Childhood chest illness and the rate of decline of adult lung function between ages 35 and 45 years. Am J Respir Crit Care Med 2007;175:355-9.

5. Barker DJ, Godfrey KM, Fall C, et al. Relation of birth weight and childhood respiratory infection to adult lung function and death from chronic obstructive airways disease. BMJ 1991;303:671-5.

6. Shaheen SO, Barker DJ, Holgate ST. Do lower respiratory tract infections in early childhood cause chronic obstructive pulmonary disease? Am J Respir Crit Care Med 1995;151:1649-52.

7. Merkus PJ, ten Have-Opbroek AA, Quanjer PH. Human lung growth: a review. Pediatr Pulmonol 1996;21:383-97.

8. Hislop AA, Wigglesworth JS, Desai R. Alveolar development in the human fetus and infant. Early Hum Dev 1986:13:1-11.

9. Wang $\mathbf{X}$, Dockery DW, Wypij D, et al. Pulmonary function growth velocity in children 6 to 18 years of age. Am Rev Respir Dis 1993;148:1502-8.

10. Burrows B, Cline MG, Knudson RJ, et al. A descriptive analysis of the growth and decline of the FVC and FEV1. Chest 1983;83:717-24.

11. Tager IB, Segal MR, Speizer FE, et al. The natural history of forced expiratory volumes. Effect of cigarette smoking and respiratory symptoms. Am Rev Respir Dis 1988:138:837-49.

12. de Marco R, Accordini S, Cerveri I, et al. An international survey of chronic obstructive pulmonary disease in young adults according to GOLD stages. Thorax 2004:59:120-5.

13. Samet JM, Tager IB, Speizer FE. The relationship between respiratory illness in childhood and chronic air-flow obstruction in adulthood. Am Rev Respir Dis 1983;127:508-23.

14. Lodrup Carlsen KC, Jaakkola JJ, Nafstad P, et al. In utero exposure to cigarette smoking influences lung function at birth. Eur Respir J 1997;10:1774-9.

15. Stick SM, Burton PR, Gurrin L, et al. Effects of maternal smoking during pregnancy and a family history of asthma on respiratory function in newborn infants. Lancet 1996;348:1060-4.

16. Gilliland FD, Berhane K, McConnell R, et al. Maternal smoking during pregnancy, environmental tobacco smoke exposure and childhood lung function. Thorax 2000;55:271-6.

17. Cook DG, Strachan DP, Carey IM. Health effects of passive smoking. 9. Parental smoking and spirometric indices in children. Thorax 1998:53:884-93.

18. Jaakkola MS, Ernst $P$, Jaakkola JJ, et al. Effect of cigarette smoking on evolution of ventilatory lung function in young adults: an eight year longitudinal study. Thorax 1991:46:907-13
19. Upton MN, Watt GC, Davey Smith G, et al. Permanent effects of maternal smoking on offsprings' lung function. Lancet 1998;352:453.

20. Svanes C, Omenaas E, Jarvis D, et al. Parental smoking in childhood and adult obstructive lung disease: results from the European Community Respiratory Health Survey. Thorax 2004;59:295-302.

21. Shaheen S0, Barker DJ, Shiell AW, et al. The relationship between pneumonia in early childhood and impaired lung function in late adult life. Am J Respir Crit Care Med 1994:149:616-9.

22. Johnston ID, Strachan DP, Anderson HR. Effect of pneumonia and whooping cough in childhood on adult lung function. N Engl J Med 1998;338:581-7.

23. Dharmage SC, Erbas B, Jarvis D, et al. Do childhood respiratory infections continue to influence adult respiratory morbidity? Eur Respir J 2009;33:237-44.

24. Lawlor DA, Ebrahim S, Davey Smith G. Association of birth weight with adult lung function: findings from the British Women's Heart and Health Study and a metaanalysis. Thorax 2005;60:851-8.

25. Canoy D, Pekkanen J, Elliott $P$, et al. Early growth and adult respiratory function in men and women followed from the fetal period to adulthood. Thorax 2007; 62:396-402.

26. Strunk RC, Weiss ST, Yates KP, et al. Mild to moderate asthma affects lung growth in children and adolescents. J Allergy Clin Immunol 2006;118:1040-7.

27. Sears MR, Greene JM, Willan AR, et al. A longitudinal, population-based, cohort study of childhood asthma followed to adulthood. N Engl J Med 2003;349:1414-22.

28. Phelan PD, Robertson CF, Olinsky A. The Melbourne Asthma Study: 1964-1999. J Allergy Clin Immunol 2002;109:189-94.

29. Chinn S, Jarvis D, Melotti R, et al. Smoking cessation, lung function, and weight gain: a follow-up study. Lancet 2005;365:1629-35.

30. Buist AS, McBurnie MA, Vollmer WM, et al. International variation in the prevalence of COPD (the BOLD Study): a population-based prevalence study. Lancet 2007:370:741-50.

31. Burgess JA, Walters EH, Byrnes GB, et al. Who remembers whether they had asthma as children? J Asthma 2006;43:727-30.

32. Svanes C, Sunyer S, Zock J, et al. Long-term reliability in reporting of childhood pets by adults interviewed twice, nine years apart. Results from the European Community Respiratory Health Survey I and II. Indoor Air 2008;18:84-92.

33. Finch CE, Crimmins EM. Inflammatory exposure and historical changes in human lifespans. Science 2004;305:1736-9.

34. James AL, Palmer LJ, Kicic E, et al. Decline in lung function in the Busselton Health Study: the effects of asthma and cigarette smoking. Am J Respir Crit Care Med 2005;171:109-14.

35. Lange $\mathbf{P}$, Parner J, Vestbo J, et al. A 15-year follow-up study of ventilatory function in adults with asthma. N Engl J Med 1998;339:1194-200.

36. Dijkstra $\mathbf{A}$, Vonk JM, Jongepier $\mathrm{H}$, et al. Lung function decline in asthma: association with inhaled corticosteroids, smoking and sex. Thorax 2006;61:105-10. 